Meta

Journal des traducteurs

Translators' Journal

\title{
El lenguaje y sus interfaces : traducción y cultura
}

\section{Ida Sonia Sãnchez}

Volume 45, numéro 4, décembre 2000

URI : https://id.erudit.org/iderudit/004026ar

DOI : https://doi.org/10.7202/004026ar

Aller au sommaire du numéro

\section{Éditeur(s)}

Les Presses de l'Université de Montréal

ISSN

0026-0452 (imprimé)

1492-1421 (numérique)

Découvrir la revue

Citer cet article

Sãnchez, I. S. (2000). El lenguaje y sus interfaces : traducción y cultura. Meta, 45(4), 683-691. https://doi.org/10.7202/004026ar

\section{Résumé de l'article}

Après avoir proposé un schéma qui inclut certaines notions recouvertes par celle de langue, telles que la traduction (en elle-même ainsi qu'en relation avec la culture et avec ses visées), de la culture (tant sur le plan individuel que collectif) et du traducteur en tant que chargé du transfert d'une culture (langue) à une autre, l'auteur questionne ce schéma en trois temps. D'abord, on se demande si la traduction a en fait la capacité de transférer complètement et sans aucune perte un énoncé d'une langue à une autre. Ensuite - et cette question découle directement de la première -, existe-t-il dans chaque langue des " es- paces culturels " pour d'autres langues, espaces permettant de rendre compte de réalités culturelles étrangères? Finalement, l'auteur illustre sa thèse à l'aide des traductions françaises et anglaises des œuvres de Borges en se demandant si la prose de ces Latino-américains a été effectivement rendue dans son intégralité.
Ce document est protégé par la loi sur le droit d'auteur. L'utilisation des services d'Érudit (y compris la reproduction) est assujettie à sa politique d'utilisation que vous pouvez consulter en ligne.

https://apropos.erudit.org/fr/usagers/politique-dutilisation/ 


\section{BLOC-NOTES}

\section{El lenguaje y sus interfaces: traducción y cultura}

\begin{abstract}
RÉSUMÉ
Après avoir proposé un schéma qui inclut certaines notions recouvertes par celle de langue, telles que la traduction (en elle-même ainsi qu'en relation avec la culture et avec ses visées), de la culture (tant sur le plan individuel que collectif) et du traducteur en tant que chargé du transfert d'une culture (langue) à une autre, l'auteur questionne ce schéma en trois temps. D'abord, on se demande si la traduction a en fait la capacité de transférer complètement et sans aucune perte un énoncé d'une langue à une autre. Ensuite - et cette question découle directement de la première -, existe-t-il dans chaque langue des «espaces culturels » pour d'autres langues, espaces permettant de rendre compte de réalités culturelles étrangères? Finalement, l'auteur illustre sa thèse à l'aide des traductions françaises et anglaises des œuvres de Borges en se demandant si la prose de ces Latino-américains a été effectivement rendue dans son intégralité.
\end{abstract}

\begin{abstract}
The author presents a model encompassing language-related concepts such as translation (translation proper, as well as translation in relation to culture and its goals), culture (considered from both individual and collective standpoints) and the translator as the agent responsible for transfer from one culture (language) to another. The model is then examined from three angles. Two related questions are raised: can translation fully convey a message from one language to another without any loss (of meaning)? Does each language allow some "cultural space" to facilitate the expression of other cultural realities? Finally, the author supports her theory using French and English translations of the works of Borges, and wonders whether full justice has been done to the prose of these Latin-American writers.
\end{abstract}

\section{MOTS-CLÉS/KEYWORDS}

langue, traduction, culture, transfert socioculturel, transfert linguistique

\section{INTRODUCCIÓN}

Consideraciones generales: La concepción del significado de la palabra como unidad que comprende tanto el pensamiento generalizado como el intercambio social es de un valor incalculable para el estudio del lenguaje. Estos dos elementos son el pivot alrededor del cual giran todas las relaciones de comunicación de cualquier tipo que fueran, en especial todas las interacciones lingüísticas y todas las manifestaciones humanas que se dirigen al otro. Esta concepción de la palabra como unidad de significación socializada es también un punto de partida para trabajar los contactos lingüísticos, nos referimos al contacto de lenguas en la traducción. El paso de una lengua a otra al ser realizado por un sujeto humano es atravesado por todos los procesos naturales que se dan en la mente y en el lenguaje. Cada individuo procesa, por así decirlo, con elementos propios de su formación lingüística, institucional y contextual todos los textos y discursos, no solamente a partir de un proceso cognitivo, sino con su acervo linguístico-social. Inmediatamente, transmite la información a un público que también procesará a su vez en la lectura o en cualquier tipo de recepción los textos y discursos. Nada es pasivo, la actividad de recepción es también un hecho probado.

Definiremos ahora en un intento de sintetizar una labor realizada por filósofos, lingüistas, antropólogos, etnólogos, psicólogos, educadores, semióticos, etc. uno de los datos últimos sobre la transferencia de una lengua a otra dentro de una perspectiva sociocomunicativa ${ }^{1}$. Esta labor ha sido realizada con esmero por un lingüista de la Universidad de Montréal, el Prof. Robert Larose, quien afirma: "La traducción es un acto de interpretación, un proceso por medio del cual el traductor interroga al texto para traducir y desentrañar su sentido. Es también un acto de producción, una práctica de escritura. En esta situación el traductor ejecuta un contrato de enunciación." (Larose 1994).

La traducción satisface cuatro condiciones de enunciación: 1. Un objetivo inicial presente. 2. El respeto del componente material. 3. El mantenimiento del nivel de la información. 4. La adecuación sociocultural entre la lengua de partida y la lengua de llegada. Esta condición es el eje sobre el que desarrollaremos los puntos esenciales de esta comunicación.

Cada individuo en su análisis del mundo tiene un marco de referencia mental. La experiencia única en cada persona conlleva modos de comprensión y de enunciación diferentes. Ahora bien, como todo texto es manifestación de una subjetividad, toda interpretación de la subjetividad del Otro es ella misma subjetiva. El margen de mediatización del traductor es evidente. La pragmática de la traducción es entonces procedural, obliga al traductor a respetar las disposiciones del contrato de enunciación. Estos factores que concurren en una acción están determinados por la creación ideológica del medio social y de la época a las cuales cada individuo pertenece. El traductor debe 
reconstituir los parámetros extralingüísticos relacionados con la situación social, e introducirse en el sentido de la enunciación completa en el tiempo y en el espacio. En esa forma revela el estado del diálogo cultural de una época dada porque la comprensión no puede ser única sino pluricultural. Una pragmática de la traducción es uno de los elementos primordiales de una cultura porque el traductor realiza la relación intertextual, establece el estado de su mundo cultural y plantea los elementos de los cuales dispone su propia cultura para acceder a los otros textos. Por ello formularemos las siguientes hipótesis: $1:$ ¿Puede la traducción apropiarse de una enunciación completa en una lengua y producir la enunciación completa en otra?. 2.¿Existen espacios culturales en una lengua "sellados" para las otras culturas? 3.¿La prosa latinoamericana de Borges, Cortázar o Mujica Láinez es totalmente captada en las traducciones al francés o al inglés?

\section{LA ADECUACIÓN DE LO SOCIO- CULTURAL ENTRE LA LENGUA DE PARTIDA Y LA LENGUA DE LLEGADA}

En líneas generales y para introducir elementos de la sociedad y de la cultura en los sistemas lingüísticos hay que remitirse a la etnografía de la comunicación y de la cultura, disciplinas que a partir de la antropología cultural se interrelacionan con la lingüística para poner en evidencia algo que es un lugar común en los desarrollos del lenguaje: la dimensión pragmática de la lengua que es su dimensión cultural.

Tanto lo funcional como lo comunicativo rehabilitan a la cultura integrada en la noción de competencia de comunicación, elaborada por Hymes quien ya aceptaba que la competencia de comunicación significa en realidad tener un conocimiento empírico de reglas lingüísticas, psicológicas y socioculturales que comandan la producción y la interpretación de la palabra en el interior de una comunicación dada. Ese concepto se aplica tanto al escrito como al oral, a la producción como a la interpretación.

Existen también zonas que facilitan la comunicación y que no dependen necesariamente de los lugares impuestos por tal emisor o tal lector-receptor sino que dependen de imponderables de la cultura. Otro aspecto interesante de la competencia de comunicación es la gradación: existen grados de competencia de comunicación en el manejo de civilizaciones o culturas diferentes a las de nuestra cultura de origen. Una competencia de comunicación implica: a) un componente lingüístico; b) un componente textual; c) un componente referencial; d) un componente relacional; e) un componente situacional.
Como vemos, ninguno de los componentes expresa formalmente lo sociocultural pero este aspecto se encuentra presente en especial en los tres últimos componentes.

En el componente referencial observamos la relación del individuo que se comunica con los diferentes dominios de la experiencia o conocimiento. ¿Cómo lo hace? ¿Qué representaciones construye el hablante de cada campo del conocimiento? ¿Cuáles son los espacios representados en las organizaciones mentales del hablante o del oyente? ¿Qué relaciones establecen los sujetos de la comunicación con las construcciones mentales?

En lo que respecta al componente relacional existe una adecuación de la palabra a las intenciones y posiciones de los participantes de la comunicación, es otro aspecto determinante del discurso, ya que cada hablante tiene también una idea de su propio discurso o del discurso en posición reflexiva. En el caso de la traducción este componente relacional permitirá la adecuación de las intenciones y posiciones del emisor y del traductor en situación de nuevo emisor.

Finalmente el componente situacional está relacionado con todos los factores que pueden afectar en una comunidad dada y en circunstancias determinadas las elecciones operadas por los usuarios de la lengua. En este componente hay rasgos similares al componente sociocultural o "connotaciones culturales" de Daniel Coste (1980: 25-34) y Sophie Moirand (1990: 41) quien reintroduce el mismo concepto en su componente sociocultural, que "es el conocimiento y la apropiación de reglas sociales $y$ de normas de interacción entre los individuos y las instituciones, el conocimiento de la historia cultural y el de las relaciones entre los objetos sociales". Esta definición encuadra el problema sociocultural en el lenguaje, que, cuando se transfiere de un sistema a otro adecua también todas las relaciones entre los objetos sociales.

\subsection{Conocimientos culturales o saberes culturales}

El término conocimiento debe ser interpretado como posesión intelectual de ciertos datos o textos propios de una colectividad determinada. Un saber se caracteriza porque tiene seis elementos: $\left.1^{\circ}\right)$ es manejado por un buen número de miembros de una colectividad dada; $2^{\circ}$ ) es el resultado de una exposición generalizada en ciertas experiencias y en ciertas instituciones; $3^{\circ}$ ) se refiere a entornos inmediatos, a la historia tradicional sobre algunas producciones lingüísticas consagradas; $4^{\circ}$ ) se supone que ese conocimiento o saber manejado es bien conocido por todos los miembros de un grupo determinado; $5^{\circ}$ ) está dotado de alguna estabilidad porque permanece tanto en la lengua del 
sistema como en la lengua de uso; $6^{\circ}$ ) a menudo está actualizado por la dinámica propia de los sistemas que lo conllevan.

También se considera importante, y esto es un aporte de la semiótica de la cultura y de los desarrollos de la psicología cognitva, que los "saberes" incluidos en la competencia de comunicación de los hablantes suponen un "saber textual mínimo", es decir el conocimiento del conjunto de lexis, versos, proverbios, rezos, frases célebres, máximas, etc., que son del dominio público y que constituyen la materia prima de la intertextualidad popular. Los discursos de la publicidad y el de los políticos apelan a este saber textual mínimo para establecer acercamientos o complicidades y a veces hasta para manipular a los receptores.

Los referentes a quienes remiten los saberes culturales se inscriben en redes relacionales diferentes según las diferentes comunidades. Podemos ver en este aspecto el punto de vista de los participantes de la comunicación, es decir que la perspectiva de un mismo saber cultural puede hacer variar la representación del mismo sin cambiar la esencia del "saber" en cuestión. En realidad se trata de convenciones semiológicas entre los grupos sociales ${ }^{2}$.

\subsection{Algunos signos o convenciones semiológicas}

Cada sociedad tiene su propio sistema de convenciones. Llamaremos "convención" la manera de interpretar o el consenso relativo que existe con respecto a algunos signos. Por ejemplo "La tour Eiffel" es entendida mundialmente como la representación de la ciudad luz: París. Para algunos grupos diferenciados es un signo que corresponde a otras nociones. Contrariamente a lo que se piensa habitualmente el área de sensibilidad y de legibilidad de un signo no es siempre función de su arbitrariedad ${ }^{3}$.

Cuando hablamos de "signos" nos situamos en la óptica del sujeto interpretante pero cuando hablamos de "comportamientos" nos situamos en la óptica del sujeto productor. Ahora bien, cuando hablamos de "competencia de comunicación" se piensa en la acción y no en la dimensión interpretativa, lo que no está siempre de acuerdo con el consumo de la lengua.

\subsection{Representaciones o visiones del mundo}

Las representaciones son creencias, valoraciones colectivas, que surgen de otras representaciones contenidas en una dimensión axiológica de la cultura.

En esta misma rúbrica entran las ideas que conciernen a las instituciones, los roles sociales, los demás, que se expresan también por aforismos, proverbios o máximas producidos y reproducidos por los centros de dominación ideológica, expresados en frases muy simples ${ }^{4}$.

Todos estos ejemplos interesan a la comprensión de esquemas de comportamientos diversos en las diferentes culturas; cuando estos esquemas o estereotipos son universales permiten acercamiento entre las sociedades y las culturas a través de las lenguas, pero cuando estas representaciones e imágenes son propias de grupos socioculturales bien discriminados con lenguas diferentes y hábitos diferentes, que crean climas o atmósferas diversas, la transferencia entre las lenguas en contacto se dificulta particularmente.

No solamente lo sociocultural sino los diferentes campos del conocimiento y los diferentes dominios de referencia son determinantes en cuanto a la red conceptual que muestra cada campo del conocimiento según su objeto de estudio y su vocabulario específico.

Pero lo sociocultural determina numerosas representaciones de los lectores aún en un mismo dominio de referencia. La traducción de los discursos técnicos y científicos plantea en algunos casos y necesariamente una reformulación del discurso en la lengua de llegada y esto ocurre porque el universo de cada individuo en el mundo de la cultura depende de los contextos en los cuales actúa y produce el conocimiento.

\section{EL POLIGLOTISMO DE LA CULTURA}

Desde el punto de vista genético, la cultura se construye sobre la base de dos lenguajes primarios. Uno de ellos es la lengua natural, utilizada por el hombre en el trato cotidiano. Su papel en la cultura es evidente. Émile Benveniste (1969) escribió: "Toda semiología de un sistema no lingüístico debe servirse de la lengua como traductor y sólo puede existir con la ayuda de la semiología de la lengua y dentro de ésta”.

El segundo lenguaje primario es el modelo estructural del espacio, Dioses, hombres, fuerzas malignas o sus sinónimos culturales son ejemplos de espacios diferentes para cada uno. Para que tal o cual sistema cumpla funciones semióticas debe poseer un mecanismo de multiplicación reiterada del objeto que constituye su significado. El mundo de la lengua natural forma una duplicación del mundo objeto y puede él mismo duplicarse en textos y lenguajes organizados y complejos. La cultura en correspondencia con esa duplicación selecciona en toda esa masa de comunicados lo que son "textos" es decir aquellos que están sujetos a una inclusión en la memoria colectiva, la memoria de todos.

La cultura es políglota porque sus textos se realizan en el espacio de por los menos dos sistemas semióticos. La fusión de la palabra y la música (el canto) y de la palabra y el gesto (la danza), en 
un único texto ritual constituyen un "sincretismo primitivo".

R. O. Jakobson señaló ya en los años 1930 que el dominio del lenguaje poético es la esfera en que se ponen de manifiesto las más importantes regularidades de la lingüística en su totalidad.

La función del texto que está ligada a la memoria de la cultura y actúa como restaurador del recuerdo, está patentada por toda la historia de la cultura de la humanidad. En este sentido los textos se convierten en símbolos integrales y funcionan sobre el eje de cada época con sentidos diferentes, así como aparecen al mismo tiempo en diferentes culturas.

\subsection{Transferencia de la lengua y transferencia de la cultura}

¿Cómo se realiza la transferencia desde el espacio semiótico de una lengua al de la otra lengua a la que se traduce?

En realidad es un proceso semiosemántico profundo, un análisis de reconocimiento y de codificación que necesita un sistema de referencia. Para todo traductor ese sistema de referencia es un metalenguaje en el cual el conocimiento de la lengua natural de partida y el conocimiento de la lengua natural de llegada debe ser codificado así como el conocimiento de la realidad reflejada por las dos lenguas, lo que significa el encuentro, en la frontera, de espacios semióticos diferentes y a través de un contacto que genera sentidos, de dos textos que son dos culturas, para producir un nuevo texto por medio de ese metalenguage que es un meta-texto, una lectura interlingüística que tiene en cuenta las restricciones de la lengua de llegada. Pero para Henri Meschonnic (1973), la traducción no es paráfrasis ni metalenguaje, sino actividad de lenguaje, donde el texto producido no es un enunciado monosémico sino que guarda su riqueza polisémica. Él es, en su nivel translingüístico, lo que es la situación de comunicación o la enunciación en el nivel lingüístico, es decir un operador de transferencia.

Con el objeto de demostrar las hipótesis planteadas en la introducción transcribiremos primero la definición dada por Jean René Ladmiral sobre la mediación interlingüística que produce la traducción: "La traducción es un caso particular de convergencia lingüística; en el sentido más amplio, designa toda forma de mediación interlingüística, permitiendo transmitir información entre locutores de lenguas diferentes. La traducción hace transitar el mensaje desde una lengua de origen $(L D)$ o lengua de partida hacia una lengua de llegada (LA) o lengua cible $(F)$ o target $(J)$. La traducción designa a la vez la práctica traductora, la actividad del traductor (sentido dinámico), y el resultado de esta actividad, el texto producido (sentido estático)...".
Es muy adecuado para nuestros propósitos, mostrar cómo una traducción al francés de Jorge Luis Borges realizada por Paul Verdevoye plantea interesantes problemas en el estudio del léxico, no así en la restitución de la enunciación y de la cohesión. Trataremos de profundizar el análisis de las diferentes conceptualizaciones para comprender las diferentes significaciones que rodean a los núcleos analizados. Tanto en español como en francés no se trata solamente de la palabra o de las palabras, sino de muchísimos factores que componen el sentido. Además existe la radiación de significaciones y las intenciones de un autor como Borges, que por más que se lea fácilmente, se comprenda y se aprecie, a veces no se puede transferir en un clima adecuado y de un modo total a otro sistema lingüístico.

El mediador interlingüístico - el traductor realiza el traslado de un conjunto cultural expresado lingüísticamente hacia otro campo cultural no del todo similar al primero. En general, el traductor se siente atraído por la novedad del acto de lengua extranjero y trata de transmitir su entusiasmo al público de su propia lengua, pero lo que generalmente no se llega a mediatizar es la atmósfera que envuelve a ese acto de lengua o la conceptualización del autor del texto original que, como un sentido evanescente y furtivo, desaparece en el intento de la transferencia.

La exploración de la cultura extranjera tiene el riesgo de destruir el edificio cultural que justifica la existencia de la identidad de origen porque las heterotopías son generalmente fuente de dificultades y de angustias. "La clasificación de los seres $y$ de las cosas varía de una cultura a la otra y frente a una taxonomía extranjera nuestro sistema de representación está cuestionado. Las distinciones inquietan sin duda porque ellas penetran secretamente el lenguaje impidiendo nombrar esto o aquello, porque cortan las palabras o las juntan, porque transforman la sintaxis y no solamente aquella que construye la frase sino aquella que parece sostener el conjunto de las palabras y las cosas." (Foucault 1966: 9).

En lo que concierne a las alusiones culturales, es decir lo implícito en el lenguaje, es necesario darse cuenta que en el seno de una misma cultura esas alusiones no son obligatoriamente percibidas y cuando se las percibe, se las percibe de manera diferente según la historia de cada individuo.

La competencia cultural de un individuo en el seno de su propio grupo social, comienza desde muy temprana edad pero no es innata, se adquiere poco a poco a través de los contactos repetidos con el entorno social.

Tenemos ejemplos en la literatura, la poesía y la plástica que tienen un sentido idiosincrásico e inherente y que al ser trasladado y mediatizado a otro contexto cultural plantea dificultades dentro 
de ese mismo sentido idiosincrásico pues el receptor extranjero al no disponer en su sistema de representaciones lingüísticas de elementos apropiados y sobre todo al no vivir, si nos remitimos a nuestro trabajo, en el contexto borgiano (argentino de Buenos Aires), a veces no es capaz de captarlo, comprenderlo y expresarlo.

En el relato "Funes el memorioso" de Ficciones de Jorge Luis Borges (1974: 485-490) traducido por Paul Verdevoye (Borges 1983: 109-118) en un pequeño texto de "Fictions" dice así:

Lo recuerdo (yo no tengo derecho a pronunciar ese verbo sagrado, sólo un hombre en la tierra tuvo derecho y ese hombre ha muerto) con una oscura pasionaria en la mano, viéndola como nadie la ha visto, aunque la mirara desde el crepúsculo del día hasta el de la noche, toda una vida entera, Lo recuerdo, la cara taciturna $y$ aindiada y singularmente remota, detrás del cigarrillo. Recuerdo (creo) sus manos afiladas de trenzador. Recuerdo cerca de esas manos un mate, con las armas de la Banda Oriental; recuerdo en la ventana de la casa una estera amarilla, con un vago paisaje lacustre. Recuerdo claramente su voz; la voz pausada, resentida y nasal del orillero antiguo, sin los silbidos italianos de ahora. Más de tres veces no lo vi; la última, en 1887... Me parece muy feliz el proyecto de que todos aquellos que lo trataron escriban sobre él: mi testimonio será acaso el más breve y sin duda el más pobre, pero no el menos imparcial del volumen que editarán ustedes. Mi deplorable condición de argentino me impedirá incurrir en el ditirambo - género obligatorio en el Uruguay cuando el tema es un urugayo. Literato, cajetilla, porteño: Funes no dijo esas injuriosas palabras, pero de un modo suficiente me consta que yo representaba para él esas desventuras. Pedro Leandro Ipuche ha escrito que Funes era un precursor de los superhombres; "Un Zarathustra cimarrón y vernáculo"; no lo discuto, pero no hay que olvidar también que era un compadrito de Fray Bentos, con ciertas incurables limitaciones.

Y la traducción dice así: "Funes ou la mémoire" (Borges 1983: 109-110).

Je me le rappelle (je n'ai pas le droit de prononcer ce verbe sacré; un seul homme au monde eut ce droit et cet homme est mort) une passionnaire sombre à la main, voyant cette fleur comme aucun être ne l'a vue, même s'il l'a regardée du crépuscule au soir, toute une vie entière. Le me rappelle son visage taciturne d'indien, singulièrement lointain derrière sa cigarette. Le me rappelle (je crois) ses mains rudes de tresseur. Le me rappelle, près de ses mains, un maté aux armes de l'Uruguay; je me rappelle distinctement sa voix, la voix posé, aigrie et nasillarde de l'ancien habitant des faubourgs sans les sifflements italiens de maintenant. Je ne l'ai pas vu plus de trois fois; la dernière en $1887 .$. Je trouve très heureux le projet de demander à tous ceux qui l'ont fréquenté d'écrire à son sujet; mon témoignage sera peut-être le plus bref et sans doute le plus pauvre, mais non le moins impartial du volume que vous éditerez. Ma déplorable condition d'Argentin m'empêchera de tomber dans le dithyrambe - genre obligatoire en Uruguay quand il s'agit de quelqu'un du pays. - Littérateur, rat de ville, Buenos-airien; Funes ne prononça pas ces mots injurieux, mais je sais suffisamment que je symbolisais pour lui ces calamités. Pedro Leandro Ipuche a écrit que Funes était un précurseur des surhommes "un Zarathoustra à l'état sauvage et vernaculaire"; je ne discute pas, mais il ne faut pas oublier qu'il était aussi un gars du bourg de Fray Bentos, incurablement borné pour certaines choses.

\section{Comentario:}

En esta pequeña selección de los dos textos (español y francés) observamos que el francés se apropia adecuadamente de los elementos enunciativos, no así de los anafóricos.

Mostraremos sólo un ejemplo de anaforización con $\underline{l o}$. En la primera línea del texto en español el pronombre $\underline{l o}$ tiene una carga de presuposición centrada en el personaje de Funes el memorioso y de lo que Funes significa antes de ser significado por el narrador ${ }^{5}$. El pronombre francés $\underline{l e}$ en la primera línea del texto en francés, no cumple la misma significación aunque sí tiene igual función. El problema proviene de la sintaxis ya que, a causa de la naturaleza del verbo se rappeler, y al ser éste un verbo pronominal, deberá llevar el $\underline{m e}$ antes del $\underline{l e}$ formando la secuencia je me le rappelle. Conceptualmente el verbo significa lo mismo pero la sintaxis desde el punto de vista de los elementos incluidos marca estilísticamente la diferencia. Ese mismo pronombre $\underline{l o}$ del español al lado del verbo recordar se reitera explícitamente en la línea cuatro. Luego, en la penúltima línea del texto español aparece delante de discutir y en el texto francés desaparece. Innumerables estudios del pronombre $\underline{l o}$ en español hablan de su carácter anafórico pero la modificación sintáctica del francés en los casos analizados produce un quiebre. Es como si la estética de la prosa de Borges sufriera en esa combinatoria del francés. Como si el conjunto de significaciones que provee la cohesión de todos los elementos observados, más la influencia de los adyascentes y más la carga significativa del léxico 
propio de ese contexto no resultara en una semiosis adecuada.

Analizaremos ahora otro elemento del léxico del español que particulariza la caracterización de Funes. En español decimos el memorioso, la selección que se hace en el sistema del francés $\underline{l a}$ mémoire no se centra sobre Funes precisamente, sino en el proceso de memoria o en el fenómeno, porque el francés no dispone de un adjetivo calificativo formado sobre el sustantivo la mémoire sí, tenemos el adjetivo francés mémorial que se aplica a monumentos, también tenemos en francés el participio presente del verbo mémoriser: en mémorisant, y otras formas con mémoire.

El memorioso en español es una caracterización apreciada por la narrativa de Borges. Borges da un rasgo de la personalidad de un protagonista con un solo adjetivo. En otro momento del cuento encontraremos el cronométrico Funes y lo mismo ocurre con el orillero.

En el caso de compadrito que también es preferido por Borges, éste se forma sobre el sustantivo compadre, y conceptualmente no es un derivado de compadre, pues más bien sería un personaje jactancioso, pendenciero que se distingue por su vestimenta y en Argentina y Uruguay es un joven arrabalero, jugador y holgazán. El francés no dispone del mismo término y no alcanza a dar todo el encanto, la sonoridad y el clima particular que produce compadrito en español. Creemos que compadrito hubiera debido ser transcripto como tal en francés para salvaguardar el espacio cultural cerrado que no corresponde exactamente a la significación de "gars du bourg" o sea muchacho de barrio, cuya polisemia puede dar lugar a varias interpretaciones $^{6}$. El encantamiento que produce la lengua de Borges puede percibirse también en francés ya que las conceptualizaciones se realizan idénticamente en el nivel semántico y se puede lograr un texto adecuado; pero la apropiación total de la relación entre la palabra, la situación y el contexto cultural implica un profundo conocimiento de las características particularísimas de la lengua del escritor argentino, una inmersión en la vida porteña y un ordenamiento sintáctico-semántico acorde con el "conocimiento del mundo" o "saberes compartidos”.

Remitiéndonos al compadrito como un personaje de la vida porteña, diremos que Borges encontraba en el compadrito y sobre todo en el malevo peleador una especie de estampa que le hubiera gustado quizá tener. En el cuento El sur esto está narrado perfectamente. En El hombre de la esquina rosada, el que más peleaba, peleaba solamente para ver si el otro era más guapo que él, no había ningún problema personal, ni de familia ni nada en el medio, solamente quería saber cuál era más guapo y nada más. Ese es el coraje que le gus- taba a Borges, el coraje porque sí. Del mismo modo que el coraje de los sajones en donde el héroe pelea con dragones para vencer en la pelea simplemente. Estas descripciones que corresponden al malevo, al compadrito y al orillero son calcos de la vida porteña de esa época pero no son, como lo creen muchos, descripciones de personas que simplemente viven en un Buenos Aires de utilería y bailan el tango (como un rasgo de la vida porteña), sino sentimientos y deseos de Borges, de su ser íntimo, que se plasma estéticamente en personajes que surgen de su sentir de Buenos Aires tal como lo dice Clemente (1998): “[...] de ser él mismo héroe, un héroe que no pudo serlo nunca por sus problemas físicos, nunca pudo ser valiente, pero lo era. El lo manifestaba con la palabra, no se calló ante ningún atisbo de injusticia, decía siempre lo que pensaba".

Por otro lado la descripción de un Buenos Aires que Borges quiere recuperar es el Buenos Aires heroico, antiguo, que admiraba el escritor, porque en realidad el heroísmo físico era lo que nunca pudo demostrar, Borges vivía en un mundo virtual, era un hombre de una profunda timidez para el mundo real.

Hemos querido hacer estas observaciones para mostrar lo que una traducción adecuada muestra de un léxico propio de la cultura y de la sociedad argentina y del conjunto de significaciones que se producen en el contacto de culturas.

Borges continúa con el texto siguiente que ya no comienza con la cláusula lo recuerdo sino con mi primer recuerdo de Funes. Evidentemente la anaforización presuposicional realizada por lo se completa magistralmente en este largo párrafo en el que "el recuerdo" repite todo lo que Borges recuerda y escribe, es como una especie de eje temático que vuelve en todos los cuentos del citado autor. El recuerdo y los sueños conforman la macroestructura global de contenido en donde se situará su prosa. En el texto en francés se realiza la anaforización y se repite el problema de la intensa presuposición de lo frente al le del francés.

Mi primer recuerdo de Funes es muy perspicuo. Lo veo en un atardecer de marzo o febrero del año 84. Mi padre, ese año, me había llevado a veranear a Fray Bentos. Yo volvía con mi primo Bernardo Haedo de la estancia de San Francisco. Volvíamos cantando, a caballo, y ésa no era la única circunstancia de mi felicidad. Después de un día bochornoso, una enorme tormenta color pizarra había escondido el cielo, La alentaba el viento del Sur, ya se enloquecían los árboles; yo tenía el temor (la esperanza) de que nos sorprendiera en un descampado el agua elemental. Corrimos una especie de carrera con la tormenta. Entramos en un callejón 
que se ahondaba entre dos veredas altísimas de ladrillo. Había oscurecido de golpe; oí rápidos y casi secretos pasos en lo alto; alcé los ojos y vi un muchacho que corría por la estrecha y rota vereda como por una estrecha y rota pared. Recuerdo la bombacha, las alpargatas, recuerdo el cigarrillo en el duro rostro, contra el nubarrón ya sin límites. Bernardo le gritó imprevisiblemente: “QQué horas son, Ireneo?”. Sin consultar el cielo, sin detenerse, el otro respondió: "Faltan cuatro minutos para las ocho, joven Bernardo Juan Francisco". La voz era aguda, burlona.

[...] Me dijo que el muchacho del callejón era un tal Ireneo Funes, mentado por algunas rarezas como la de no darse con nadie y la de saber siempre la hora, como un reloj. Agregó que era hijo de una planchadora del pueblo, María Clementina Funes, y que algunos decían que su padre era un médico del saladero, un inglés O'Connor, y otros un domador o rastreador del departamento del Salto. Vivía con su madre, a la vuelta de la quinta de los Laureles.

[...] Pregunté, como es natural, por todos los conocidos $y$, finalmente, por el "cronométrico Funes". Me contestaron que lo había volteado un redomón en la estancia de San Francisco, y que había quedado tullido, sin esperanza. Recuerdo la impresión de incómoda magia que la noticia me produjo: la única vez que yo lo vi, veníamos a caballo de San Franciso y él andaba en un lugar alto; el hecho, en boca de mi primo Bernardo, tenía mucho de sueño elaborado con elementos anteriores. Me dijeron que no se movía del catre, puestos los ojos en la higuera del fondo o en una telaraña. En los atardeceres, permitía que lo sacaran a la ventana. Llevaba la soberbia hasta el punto de simular que era benéfico el golpe que lo había fulminado... Dos veces lo vi atrás de la reja, que burdamente recalcaba su condición de eterno prisionero: una, inmóvil, con los ojos cerrados; otra, inmóvil también, absorto en la contemplación de un oloroso gajo de santonina.

Y Paul Verdevoye dice:

Mon premier souvenir de Funes est très net. Je le vois une fin d'après-midi de mars ou de février de quatre-vingt-quatre. Cette année-là, mon père m'avait emmené passer l'été à Fray Bentos. Je revenais de l'estancia de San Francisco avec mon cousin Bernardo Haedo. Nous rentrions en chantant, à cheval; et cette promenade n'était pas la seule raison de mon bonheur. Après une journée étouffante, des nuages énormes couleur d'ardoise avaient caché le ciel. Le vent du sud excitait l'orage; déjà les arbres s'affolaient; je craignais (j'espérais) que l'eau élémentaire nous surprît en rase campagne.
Nous fimes une sorte de course avec l'orage. Nous entrâmes dans une rue qui s'enfonçait entre deux très hauts trottoirs en brique. Le temps s'était obscurci brusquement; j'entendis des pas rapides et presque secrets au-dessus de ma tête; je levai les yeux et vis un jeune garçon qui courait sur le trottoir étroit et défoncé comme sur un mur étroit et défoncé. Je me rappelle son pantalon bouffant, ses espadrilles; je me rappelle sa cigarette dans un visage dur, pointant vers le gros nuage déjà illimité. Bernard lui cria imprévisiblement: "Quelle heure est-il Irénée?» Sans consulter le ciel, sans s'arrêter, l'autre répondit: «Dans quatre minutes, il sera huit heures, monsieur Bernardo Juan Francisco». Sa voix était aiguë, moqueuse.

[...] Il me dit que le jeune garçon rencontré dans la rue était un certain Irénée Funes, célèbre pour certaines bizarreries. Ainsi, il ne fréquentait personne et il savait toujours l'heure, comme une montre. Mon cousin ajouta qu'il était le fils d'une repasseuse du village, María Clementina Funes; certains disaient que son père, un Anglais, O'Connor, était médecin à la fabrique de salaisons et les autres dresseur ou guide du département du Salto. Il habitait avec sa mère, à deux pas de la proprieté des Lauriers...

[...] Naturellement, je demandai des nouvelles de toutes les connaissances et, finalement, $d u$ «chronométrique Funes». On me répondit qu'il avait été renversé par un cheval demisauvage, dans l'estancia de San Francisco, et qu'il était devenu infirme irrémédiablement. Je me rappelle l'impression magique, gênante que cette nouvelle me produisit: la seule fois que je l'avais vu, nous venions à cheval de San Francisco, et il marchait sur un lieu élevé; le fait, raconté par mon cousin Bernardo, tenait beaucoup du rêve élaboré avec des éléments antérieurs. On me dit qu'il ne quittait pas son lit, les yeux fixés sur le figuier $d u$ fond ou sur une toile d'araignée. Au crepuscule, il permettait qu'on l'approchât de la fenêtre. Il poussait l'orgueil au point de se comporter comme si le coup qui l'avait foudroyé était bienfaisant... Je le vis deux fois derrière la grille qui accentuait grossièrement sa condition d'éternel prisonnier: une fois, immobile, les yeux fermés; une autre, immobile aussi, plongé dans la contemplation d'un brin odorant de santonine.

\section{Comentario:}

El tema del tiempo aparece nuevamente en Borges describiendo su propio tiempo, el del recuerdo, el tiempo del relato y el tiempo de Funes cuando dice el cronométrico Funes transcripto perfectamente en francés. Nuevamente debemos mencionar en este estudio la anaforización restituida con los mismos 
elementos gramaticales y lexicales a las que agregaremos algunas particularidades de las frases catafórico-anafóricas como sucede en las líneas 16, 17 y 18 del texto en español y en las líneas 18 y 19 del texto en francés de estos dos últimos párrafos estudiados. Esta relación cohesiva lexical, anunciada catafóricamente por algunas rarezas es explicada por dos elementos en contigüidad, la de no darse con nadie - frase negativa - y la de saber siempre la hora como un reloj - frase afirmativa que puntualiza la característica de Funes de "ser como un reloj". Si no hubiéramos tenido en el texto francés la posibilidad de utilizar el verbo fréquenter, la negación: personne, (un elemento de la negación) que es nadie, no habría llenado el espacio cultural del texto, expresado por la lexía: no darse con nadie, sintácticamente correcta. Felizmente, esta frase il ne fréquentait personne más et il savait toujours l'heure, comme une montre surge como un engarce del eje temático del texto de Verdevoye, muy ajustado al original.

Otro adjetivo interesante de la prosa de Borges es el adjetivo elemental, tanto en su poesía como en este cuento aparece repetidas veces, al lado de agua, como queriendo remitirse a lo más primitivo de la naturaleza, aquello que lo transformaba en un elemento de unión entre sus sueños y la realidad por él expresada, un símbolo generador de sentidos, en francés se respeta siempre ese concepto. En dos o tres oportunidades estas relaciones anafóricas lexicales y esos adjetivos que se repiten a lo largo del texto, también anafóricos tejen la coherente temática de Borges dentro del mundo latinoamericano pero sobre todo argentino, en el que las características de la vida porteña son descriptas y reformuladas con una estética cultural propia. El texto francés se acerca mucho al español.

Pero hay algo más, toda esa fusión del Buenos Aires nostálgico de Borges y del sentir íntimo del autor es el testimonio de la presencia efectiva de las cosas y de los hechos con una firmeza convincente. Ello sólo se logra y se percibe en el amplio y particular léxico del español del Río de la Plata, es el "encantamiento" propio de la lengua de Borges que tiene una distinción especial. A veces, sólo a veces se logra cierto clima similar, pero no igual en las traducciones, es que el texto traducido por sí solo no puede generar nada, él debe entrar en relación con la cultura y con el auditorio para que se realicen sus posibilidades generativas. $Y$ las posibilidades de sentido que Borges confiere a sus textos está en el despliegue de las estructuras pero también en la interacción de las mismas.

\section{CONCLUSIÓN}

Borges tiene una gran capacidad para la economía y para la síntesis del lenguaje. Su sintaxis es senci- lla, su idioma concreto. Es un español culto, muy fino, muy visible, y esa capacidad de mostrar con las palabras (se ven las palabras en Borges) dificulta a veces la transferencia en traducción. Es posible que un trabajo que considere todas las radiaciones de una semiosis del contacto de las dos culturas que se manejan en este estudio: la argentina y la francesa pueda proporcionar elementos valiosos en el análisis de la transferencia en traducción.

Hemos tratado de colaborar con un estudio contrastivo focalizado en la restitución de la enunciación y de la cohesión en los cuentos de Borges en español, traducidos al francés, por tratarse de estructuraciones discursivas que proponen análisis semióticos perfectamente delimitados en un universo estructurado. Estos textos borgianos nos han permitido también observar las codificaciones posibles en la literatura y las interacciones permanentes de esos códigos que resultan un proceso de la semiosis dentro de muchos otros alimentados en la pluralidad de sistemas y de códigos por medio de los cuales se realizan y que naturalmente los desbordan.

También es importante la creación de símbolos culturales latinoamericano-argentinos, la transferencia de esos símbolos culturales al francés, no sin dificultad y la generación de nuevos sentidos en la intertextualidad que propone la lengua de Borges. Recordemos que Claude Lévi-Strauss (1990: 207 y 206) decía que: "Chaque culture se développe grâce à ses échanges avec d'autres cultures. Mais il faut que chacune y mette quelque résistance. Car, si c'est la différence des cultures qui rend leur rencontre féconde [...] ce jeu en commun entraîne leur uniformisation progressive. ${ }^{7}$

Mucho nos queda por realizar, esto es sólo el inicio de la tarea.

\section{NOTAS}

1. Es necesario destacar que en contextos sociogeográficos bilingües se desarrolla espontáneamente una capacidad complementaria de la competencia lingüística que todo individuo posee para comprender las lenguas y captar su sentido, es el caso del Canadá, en el que se ha desarrollado un aparato institucional en el estado capaz de sostener un país bilingüe, con servicios lingüísticos adecuados y con investigaciones que proveen a los científicos de interesantísimas experiencias para profundizar la relación pensamiento-lenguaje en la traducción.

2. Ejemplificaremos este tipo de saber con "el velorio" o reunión que se hace para despedir a un difunto en la Argentina y en los Estados Unidos. Aun dentro de la Argentina la despedida de los difuntos en el Norte (en Jujuy con cantos y bailes) es totalmente diferente a la de Buenos Aires en el sur. 
3. Un "ícono" aunque se funda sobre un principio de analogía sólo tiene valor para el que reconoce y sabe qué referente representa a través del "signo" que lo contiene. Un "indicio" sólo es reconocido en relación a un sistema cultural preciso, por ejemplo, una mujer vestida de blanco en la India indica que está de luto. Una mujer que está vestida de negro en Italia indica que está de luto o es una mujer casada, de cierta edad. Por el contrario, existen signos arbitrarios que tienen un campo de extensión inmenso, como, la cruz roja.

4. La famosa máxima "No se puede ser más papista que el Papa" es conocida en nuestro contexto social cristiano. La misma máxima aplicada al contexto del siglo XVIII francés decía "On ne peut pas être plus royaliste que le Roi" cuya traducción en español es: "No se puede ser más realista que el Rey". La idea principal de esta máxima concierne a las instituciones: la Iglesia y el Estado quienes están presentes de alguna manera en la vida de los individuos y de la sociedad.

5. En el segundo texto que analizaremos se encuentra la descripción de Funes, el protagonista del cuento.

6. En una reciente consulta con el Prof. Bernard Pottier, reconocido semántico francés, estudiamos la posibilidad de hacer la correspondencia de compadrito con un gamin de París, lo que no nos pareció totalmente adecuado ya que históricamente este término sería mucho más antiguo que compadrito de Borges y ciertamente en dos contextos totalmente diferentes.

7. Cada cultura se desarrolla gracias al intercambio con otras culturas, pero es necesario que cada una ponga allí alguna resistencia. Porque si es la diferencia de culturas la que hace su encuentro fecundo [...] ese juego en común acarrea su uniformación progresiva. (Lévi-Strauss 1990)

IDA Sonia SÃNCHeZ Universidad Nacional de Tucumán, San Miguel de Tucumán, Argentine

\section{BIBLIOGRAFÍA}

Benveniste, É. (1969): «Sémiologie de la langue (2)», Semiótica, 1-2.

Borges, J. L. (1974): “Obras Completas. 19231972. Ficciones. Artificios,” Buenos Aires, Emecé Editores.
_ (1983): «Funes ou la mémoire», Fictions, trad. P. Verdevoye, I. et R. Caillois, Buenos Aires, Emecé Editores, 1956 et 1960; Paris, Gallimard, 1957 et 1965 pour la traduction française.

Clemente, J. E. y O. Sbarra Mitre (1998): Borges, director de la Biblioteca Nacional. Diálogos, Buenos Aires, Biblioteca Nacional, col. "Fin del Milenio".

Coste, D. (1980): «Communicatif, fonctionnel, notionnel et quelques autres», Le français dans le monde, 153, p. 25-34.

Hymes, D. H. (1972): «On communicative competence», Sociolinguistics (Pride and Holmes, eds.), London, Penguin.

Kerbrat-Orecchioni, C. (1997): La enunciación. De la subjetividad en el lenguaje, $3^{\text {a }}$ ed., Buenos Aires, Edicial.

Ladmiral, J.-R. (1979): Traduire. Théorèmes pour la traduction, Paris, Payot.

LARose, R. (1994): Qualité et efficacité en traduction, Montréal, Séminaire Université de Montréal.

- (1989): Théories contemporaines de la traduction, Presses de l'Université du Québec.

LOTMAN, I. M. (1996): La semiósfera I, Universidad de Valencia, Cátedra, p. 90-93.

Ludskanov, A. (1975): "A Semiotic Aproach to the Theory of Translation," Language Sciences, 35 (April 1975).

Malinowski, B. (1968): Une théorie scientifique de la culture, Paris, Maspero (réimpr. dans coll. «Points», $\mathrm{n}^{\circ} 2$; trad. fr. d'A Scientific Theory of Culture and Other Essays, University of North Carolina Press, 1944).

Meschonnic, H. (1973): Pour la poétique II, Paris, Gallimard.

Moirand, S. (1990): «Lecture de textes de spécialité en français langue étrangère», séminaire, Buenos Aires, Rosario, Argentina, 5-19 de mayo de 1990.

Mounin, G. (1963): Les problèmes théoriques de la traduction, Paris, Gallimard.

Pierce, C. (1995): 5.470 y ss. citado por Eco en su Tratado de Semiótica General-Ediciones Lumen-Quinta Edición. Pág. 117.

Verdevoye, P., I. et R. Caillois (1983): Fictions, Paris, Gallimard, coll. «Folio». 